\title{
Structure- and Coverage-Sensitive Mechanism of NO Reduction on Platinum Electrodes
}

\author{
Ioannis Katsounaros, ${ }^{*} \dagger \odot$ Marta C. Figueiredo, Xiaoting Chen, Federico Calle-Vallejo, ${ }^{* \odot}$ \\ and Marc T. M. Koper*๑
}

Leiden University, Leiden Institute of Chemistry, Einsteinweg 55, 2300 RA Leiden, The Netherlands

\section{Supporting Information}

\begin{abstract}
The interaction of nitric oxide with metal surfaces has been a traditional model system for (electrochemical) surface science. Moreover, $\mathrm{NO}$ is an important intermediate within the currently imbalanced nitrogen cycle. Here, we study the electrochemical reduction of adsorbed $\mathrm{NO}$ on $\mathrm{Pt}(111)$ and $\mathrm{Pt}(100)$ electrodes by means of experimental and computational tools. Using linear sweep voltammetry, we find that the onset potentials on $\mathrm{Pt}(111)$ for the reduction of $* \mathrm{NO}$ on top and on fcc hollow sites (approximately +0.40 and $+0.25 \mathrm{~V}_{\mathrm{RHE}}$, respectively) are independent of the surface coverage. On the other hand, *NO adsorbed at a low coverage on $\mathrm{Pt}(100)$ is more reactive than a compact, saturated *NO

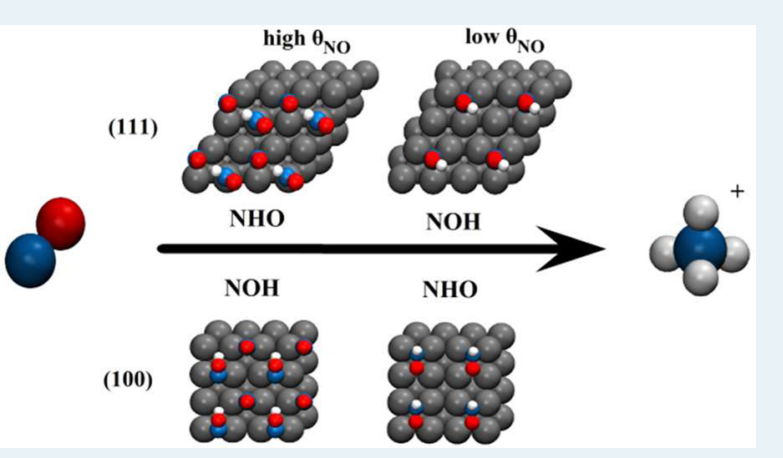
adlayer is, and the reaction kinetics switches from first- to secondorder from high to low coverage. Density functional theory calculations offer an explanation for the experimental observations by suggesting that the stability of the first hydrogenation product (*NHO or $* \mathrm{NOH})$ and thus the reaction mechanism strongly depends on the *NO coverage and the surface facet. Therefore, ${ }^{*} \mathrm{NO}$ reduction on platinum exemplifies a reaction in which not only the rate but also the mechanism is sensitive to structure and coverage. These observations hint at the need for a wider scope in materials design methodologies, as facet- and coverage-independent reaction pathways are typically used for materials screening.
\end{abstract}

KEYWORDS: NO reduction, electrocatalysis, reaction mechanism, structure sensitivity, adsorbate coverage, computational materials design

\section{INTRODUCTION}

Nitric oxide (NO) is an important intermediate during many reactions within the nitrogen cycle, so that its efficient conversion is paramount in environmental terms. ${ }^{1,2}$ In addition, the interaction of NO with metal surfaces is a typical system for fundamental studies in (electrochemical) surface science and catalysis. $^{3-5}$ The electroreduction of NO offers an excellent opportunity to study a model multielectron reaction that involves a wide spectrum of intermediate and final products. ${ }^{2}$

The reductive stripping of NO adsorbed on low- and highindex Pt single crystals has been studied previously for saturated NO adlayers. ${ }^{5-14}$ Here, we compare the reactivity and stability of low-coverage and saturated nitric oxide layers on $\mathrm{Pt}(111)$ and $\mathrm{Pt}(100)$ by means of (spectro)electrochemical experiments and density functional theory (DFT) calculations. We revisit this reaction to illustrate how the interplay of several factors can alter the mechanism of a catalytic reaction. Our findings show that the preferred catalytic pathway for $\mathrm{NO}$ on $\mathrm{Pt}$ catalysts depends not only on the geometric arrangement of its surface atoms but also on the coverage of spectators and adsorbed intermediates and, interestingly, on the ability of the latter to modify their adsorption configuration without substantially affecting the overall adsorption energies. All these diverse mechanistic features are, however, masked by the fact that the final product of $\mathrm{NO}$ reduction on $\mathrm{Pt}$ is typically $\mathrm{NH}_{4}^{+}$, independent of the $\mathrm{Pt}$ facet or surface coverage.

The deconvolution of these effects widens the current notion of structural sensitivity in catalysis, which typically describes the impact of the surface structure on reactivity. ${ }^{15-17}$ In particular for electrocatalysis, structure-activity relationships are attributed to the structure-sensitive adsorption of a reactant, intermediate, or electrolyte spectator, the relative stability of which changes the reaction rate. ${ }^{18-20}$ However, an important fact is often overlooked: beyond a mere change in rate, changes in the catalyst's morphology and coverage of adsorbates may also change the reaction mechanism. ${ }^{21-23}$ This brings new ideas that need to be taken into account in materials design, where successful and widespread methodologies have helped in the design of new catalysts for hydrogen evolution, ${ }^{24}$ oxygen reduction, ${ }^{25-27}$ oxygen evolution, ${ }^{28,29}$ and carbon dioxide reduction. ${ }^{30}$ Such designs were, however, based on low- or constant-coverage energetics and/or on a single facet, and further enhancement could, therefore, result from a wider structural sensitivity perspective.

Received: $\quad$ March 31, 2017

Revised: $\quad$ May 29, 2017

Published: June 5, 2017 


\section{METHODS}

2.1. Experimental Details. The electrolyte was an Arsaturated $0.1 \mathrm{M} \mathrm{HClO}_{4}$ solution prepared with concentrated $\mathrm{HClO}_{4}$ (70\%, Merck Suprapur) and ultrapure water [Merck Millipore, 18.2 $\mathrm{M} \Omega \mathrm{cm}$, total organic carbon (TOC) of $<3$ $\mathrm{ppb}$. All experiments were performed in glass cells, using a platinum counter electrode and a reversible hydrogen reference electrode (RHE). The linear sweep voltammograms were recorded from +0.85 to $+0.07 \mathrm{~V}_{\mathrm{RHE}}$ at a rate of $2 \mathrm{mV} \mathrm{s}^{-1}$; the cyclic voltammograms of the $\mathrm{NO}$-free $\mathrm{Pt}$ surfaces were recorded at a rate of $50 \mathrm{mV} \mathrm{s}^{-1}$. All glassware was cleaned in an acidic solution of potassium permanganate overnight, followed by rinsing with an acidic solution of hydrogen peroxide and repetitive rinsing and boiling with ultrapure water. The electrochemical measurements were performed with the single-crystal electrode in the hanging meniscus configuration. The potential was controlled with an Autolab PGSTAT302N potentiostat. The current density shown herein represents the measured current normalized to the geometric area of the working electrode.

2.2. Preparation of NO Adlayers. The single-crystal electrodes were $\mathrm{Pt}$ beads (kindly provided by J. Feliù, University of Alicante, Alicante, Spain) or platinum disks (Mateck $\mathrm{GmbH}$ ) for the electrochemical or infrared measurements, respectively. To ensure the proper surface ordering, the electrodes were prepared as previously described. ${ }^{31,32}$ Briefly, prior to each measurement, the crystals were flame-annealed and cooled to room temperature in an $\mathrm{Ar} / \mathrm{H}_{2}$ (3:1) environment. Subsequently, the crystal was protected with a drop of water saturated in the same gas mixture and transferred (unless otherwise stated) to an acidic solution of sodium nitrite, in which nitric oxide forms spontaneously via the equilibrium ${ }^{33}$

$$
3 \mathrm{HNO}_{2} \rightleftarrows \mathrm{HNO}_{3}+2 \mathrm{NO}+\mathrm{H}_{2} \mathrm{O}
$$

The single-crystalline surface was in contact with this solution for $60 \mathrm{~s}$, which is sufficient to form a complete layer of NO. Afterward, the crystal was thoroughly rinsed with ultrapure water to prevent any contamination from the acidic nitrite solution and transferred to the (spectro)electrochemical cell at $+0.85 \mathrm{~V}_{\mathrm{RHE}}$ where the NO layer is stable toward either reduction or oxidation. The successful ex situ NO adsorption and complete blockage of the electrode were verified prior to recording the linear sweep voltammograms with cycles between +0.85 and $+0.55 \mathrm{~V}_{\mathrm{RHE}}$, in accordance to the methodology described by Rodes et al.

2.3. In Situ Infrared Spectroscopy. The in situ spectroscopy measurements were performed with a Bruker Vertex $80 \mathrm{v}$ vacuum spectrometer in the external reflection mode, using an MCT detector and p-polarized light. The spectroelectrochemical cell was similar to the one described previously by Iwasita and $\mathrm{Nart}^{34}$ and the experiments were performed in the thin layer configuration. Each spectrum represents the average of 100 interferograms collected with a resolution of $8 \mathrm{~cm}^{-1}$. The spectra were intentionally recorded under potentiostatic conditions to allow a high signal-to-noise ratio while the compounds are at a steady state. The spectra are shown as $\left(R-R_{0}\right) / R_{0}$, where $R$ and $R_{0}$ are the reflectance at the sample and reference potential, respectively. In this way, for the spectra presented in this work, positive bands correspond to species in excess at the sample potential with respect to the reference potential and negative bands to species that are deficient at the sample potential with respect to the reference potential.

2.4. Computational Details. The DFT calculations were performed with the VASP code, ${ }^{35}$ using the projector augmented-wave method ${ }^{36}$ and the PBE exchange-correlation functional. ${ }^{37}$ The $2 \times 2$ (111) slabs contained four metal layers: the two topmost were allowed to relax in all directions, whereas the other two were fixed at the bulk distances. The $2 \times 2$ (100) slabs contained five metal layers: the three topmost were allowed to relax in all directions, whereas the other two were fixed. The different choice of slab thickness for $\mathrm{Pt}(111)$ and $\mathrm{Pt}(100)$ is motivated by recent findings ${ }^{38}$ and is explained in section S4 of the Supporting Information. In all cases, the adsorbates were allowed to relax in all directions. The relaxations were made with a plane-wave cutoff of $450 \mathrm{eV}$ and a $k_{\mathrm{B}} T$ of $0.2 \mathrm{eV}$ using the conjugate-gradient scheme until the maximal force on any atom was $<0.05 \mathrm{eV}^{-1}$, and we took the extrapolated total energies at $0 \mathrm{~K}$. We used MonkhorstPack meshes ${ }^{39}$ of $6 \times 6 \times 1$ for both surfaces, which ensured convergence of the adsorption energies below $0.05 \mathrm{eV}$. The distance between periodic images in the $z$ direction was at least $14 \AA$, and dipole corrections were used. Isolated $\mathrm{NO}, \mathrm{H}_{2} \mathrm{O}$, and $\mathrm{H}_{2}$ were simulated in cubic boxes of $15 \AA \times 15 \AA \times 15 \AA$ using the $\Gamma$ point and a $k_{\mathrm{B}} T$ of $0.001 \mathrm{eV}$. The free energies of adsorption were calculated from the DFT total energies as $\Delta G$ $=\Delta E_{\mathrm{DFT}}+\Delta \mathrm{ZPE}-T \Delta S+\Delta E_{\text {solvation, }}$ where ZPE is the zeropoint energy and $T \Delta S$ is the entropy correction at $298.15 \mathrm{~K}$, corresponding to the sum of all types of entropy for $\mathrm{NO}, \mathrm{H}_{2} \mathrm{O}$, and $\mathrm{H}_{2}$, and vibrational entropy for the adsorbates. We modeled proton-electron transfers with the computational hydrogen electrode. ${ }^{40}$ There are currently three common ways of accounting for solvation in aqueous electrocatalysis: (1) explicitly, i.e., including water molecules in each calculation, which can be done using molecular dynamics ${ }^{41}$ or static calculations; $^{42,43}$ (2) implicitly, i.e., representing water by a continuum with a suitable dielectric constant; ${ }^{44,45}$ and (3) by a constant shift to the adsorption energies calculated in vacuum that depends on the chemical nature of the solvent and adsorbate. $^{45-47}$ In our study, we took the values calculated explicitly by Greeley and co-workers using ab initio molecular dynamics. ${ }^{41}$ We added those values to the adsorption energies in vacuum to account for the solvent stabilization. Regardless of the method used to account for solvation, the result should depend on adsorbate and spectator coverage, because steric hindrance prevents or at least weakens the stabilizing interaction between adsorbates and solvent molecules. Note that the solvation corrections reported for the adsorbates for low $* \mathrm{NO}$ coverage are, in principle, equal or larger than those for high $* \mathrm{NO}$ coverage. Thus, we used the same solvation corrections for both coverage regimes and note that future studies could benefit from the incorporation of coveragedependent solvation corrections.

\section{RESULTS AND DISCUSSION}

\subsection{Adsorption Configurations of $\mathrm{NO}$ on $\mathrm{Pt}(111)$ and} $\mathrm{Pt}(100)$ from DFT. From electronic structure calculations, we find that the most stable adsorption site for $\mathrm{NO}$ on $\mathrm{Pt}(111)$ is the fcc hollow at $\theta_{*_{\mathrm{NO}}}=0.25 \mathrm{ML}$, while at $0.5 \mathrm{ML}$ atop $* \mathrm{NO}$ co-adsorbs. The calculated $\mathrm{N}-\mathrm{O}$ stretching frequencies at $\theta_{* \mathrm{NO}}$ $=0.5 \mathrm{ML}$ are 1486 and $1766 \mathrm{~cm}^{-1}$ for the NO adsorbed on the fcc and top sites, respectively. On $\mathrm{Pt}(100)$, bridge-adsorbed $\mathrm{NO}$ is the most stable configuration at any coverage of $\leq 0.5$ ML. Two vibrational frequencies were calculated at $\theta_{* \mathrm{NO}}=0.5$ 
ML at 1688 and $1623 \mathrm{~cm}^{-1}$, for symmetric and antisymmetric $\mathrm{N}-\mathrm{O}$ stretching, respectively. A detailed description of the calculated energies for $\mathrm{NO}$ adsorption on different sites on $\mathrm{Pt}(111)$ and $\mathrm{Pt}(100)$ and the corresponding $\mathrm{N}-\mathrm{O}$ stretching frequencies are shown in section $\mathrm{S} 1$ of the Supporting Information (see Tables S1 and S2).

3.2. Reduction of $* \mathrm{NO}$ on $\mathrm{Pt}(111)$. We studied the reduction of pre-adsorbed * $\mathrm{NO}$ by linear sweep voltammetry (LSV), starting from $+0.85 \mathrm{~V}_{\mathrm{RHE}}$ (where ${ }^{*} \mathrm{NO}$ is stable) and scanning toward lower potentials. For the saturated $*$ NO layer on $\mathrm{Pt}(111)$ (black curve in Figure 1a), the characteristic "butterfly" features for $\operatorname{Pt}(111)$ observed in the blank voltammetry in the potential region from +0.85 to $+0.5 \mathrm{~V}_{\mathrm{RHE}}$ are absent, which suggests that the surface is completely blocked by adsorbed NO. ${ }^{7}$ With a further decrease in the potential, *NO reduction occurs with two waves located at approximately +0.32 and $+0.14 \mathrm{~V}$. The two waves have been assigned to the reduction of $\mathrm{NO}$ adsorbed on top and fcc hollow sites, respectively, ${ }^{14}$ which are the most stable adsorption sites at high coverage as described above.

We utilized in situ Fourier transform infrared spectroscopy (FTIR) to characterize the NO adlayer as well as adsorbed and desorbed reduction products as a function of the potential (Figure 1c,d). A reference spectrum was first recorded at +0.85 $\mathrm{V}_{\mathrm{RHE}}$, and sample spectra were then recorded sequentially at $+0.85,+0.50$, and $+0.20 \mathrm{~V}_{\mathrm{RHE}}$. The spectra at $+0.85 \mathrm{~V}_{\mathrm{RHE}}$ show no features because they were collected in principle under the same conditions as the reference spectrum, to ensure the stability of the thin layer. At $+0.50 \mathrm{~V}_{\mathrm{RHE}}$, a symmetric bipolar band centered at $1689 \mathrm{~cm}^{-1}$ was observed, with a negative counterpart at $1697 \mathrm{~cm}^{-1}$ and a positive counterpart at 1670 $\mathrm{cm}^{-1}$ (Figure $1 \mathrm{~d}$ for $\mathrm{D}_{2} \mathrm{O}$ ). The frequency of the vibrational bands of adsorbed species can shift when the electrode potential is varied, and this effect is known as Stark tuning. ${ }^{48}$ As a consequence, bipolar bands arise from the change in the band position with potential for adsorbed species without a change in coverage. The observation of a bipolar band in the spectra from +0.85 to $+0.50 \mathrm{~V}_{\mathrm{RHE}}$ shows that $\mathrm{NO}$ remains adsorbed in this potential range without a decrease in NO coverage. $^{7}$ At $+0.2 \mathrm{~V}_{\mathrm{RHE}}$, only the negative band at $1697 \mathrm{~cm}^{-1}$ was observed, which implies that the NO that was adsorbed at the reference potential $\left(+0.85 \mathrm{~V}_{\mathrm{RHE}}\right)$ has been depleted at the sample potential $\left(+0.2 \mathrm{~V}_{\mathrm{RHE}}\right)$ (Figure $1 \mathrm{~d}$ ). We assign this band to $\mathrm{NO}$ adsorbed on top sites because this is expected from previous DFT studies, ${ }^{4,49-52}$ and from our DFT calculations (see Table S2). Moreover, it has been previously shown that the species that give rise to the band in the region of 1670$1697 \mathrm{~cm}^{-1}$ are not present at the surface at potentials as positive as $+0.3 \mathrm{~V}_{\mathrm{RHE}} .{ }^{12,14}$ Another band would be expected for NO adsorbed in the fcc hollow site at lower wavenumbers (see Table S2). Neither our results in Figure 1d nor other previous studies have shown such a band, ${ }^{5,7}$ which is most likely related to the low band intensity. The positive band at $1461 \mathrm{~cm}^{-1}$ at $+0.2 \mathrm{~V}_{\mathrm{RHE}}$ (Figure 1c for $\mathrm{H}_{2} \mathrm{O}$ ) is attributed to dissolved $\mathrm{NH}_{4}{ }^{+}$ and thus indicates that the latter is the main product of the reduction of adsorbed $\mathrm{NO}$, as also suggested previously. ${ }^{12,14}$ Moreover, a weak positive band is observed at $2230 \mathrm{~cm}^{-1}$ at the same potential (Figure 1c). This band is attributed to $\mathrm{N}_{2} \mathrm{O}$ dissolved in the solution, as confirmed by the transmission spectrum. $\mathrm{N}_{2} \mathrm{O}$ formation was observed previously with $\mathrm{NO}$ in solution and was attributed to an Eley-Rideal (E-R) mechanism. $^{41,53}$ The fact that $\mathrm{N}_{2} \mathrm{O}$ forms here with $\mathrm{NO}$ present only at the surface proves that recombination of
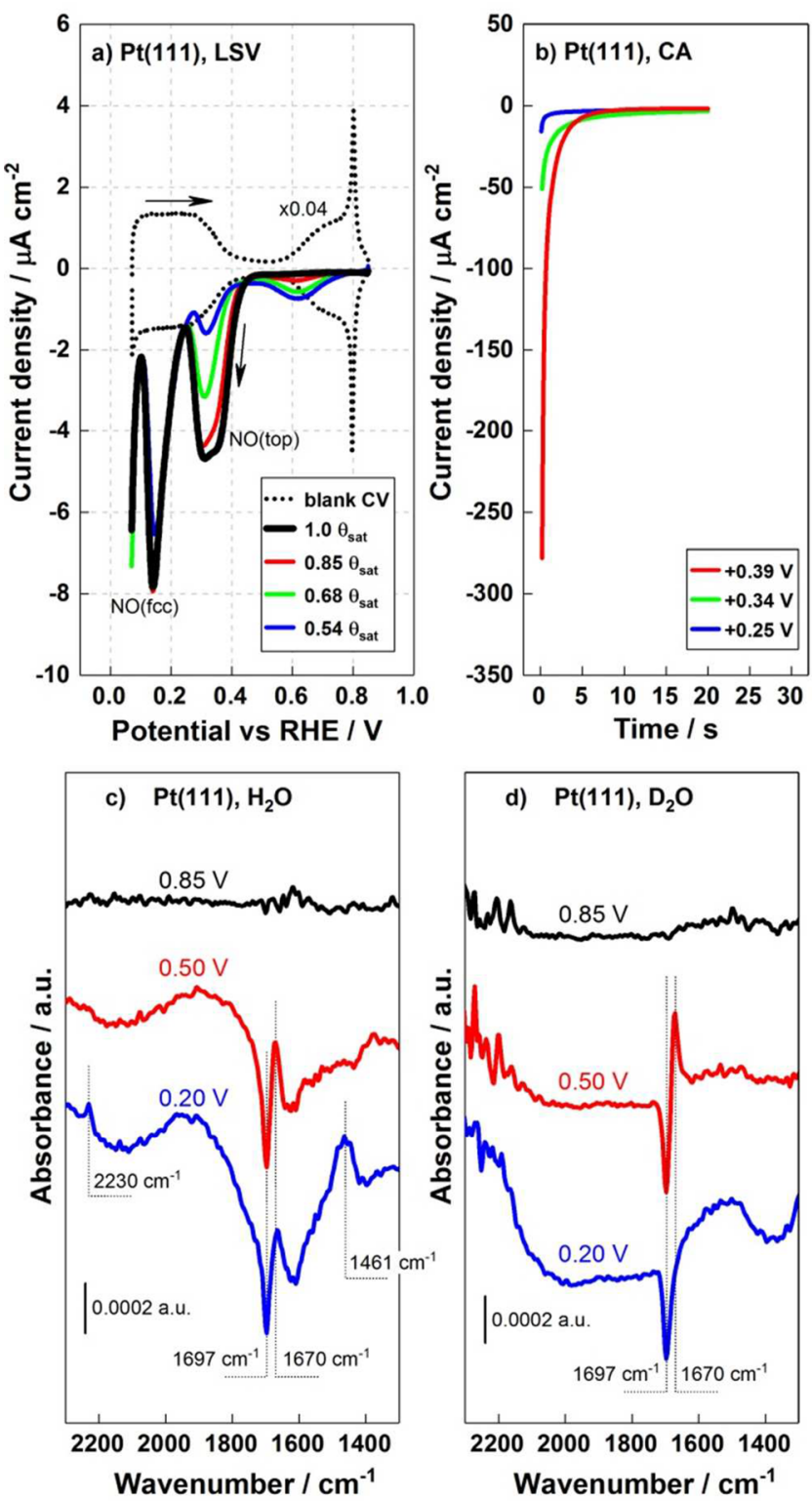

Figure 1. Electrochemical reduction of $\mathrm{NO}$ on $\mathrm{Pt}(111)$ in $0.1 \mathrm{M}$ $\mathrm{HClO}_{4}$. (a) Linear sweep voltammograms (negative direction) for saturated and unsaturated $\mathrm{NO}$ adlayers recorded at $2 \mathrm{mV} \mathrm{s}^{-1}$. The unsaturated layers were generated by partial reduction of a saturated layer using chronoamperometry. The coverages in the caption were calculated by the charge in the chronoamperometric transient. The blank voltammograms for the NO-free surface recorded with $50 \mathrm{mV}$ $\mathrm{s}^{-1}$ and scaled as shown in the index are included for comparison. The arrows indicate the direction of the scan. (b) Current-time transients during chronoamperometry at an $E_{\text {step }}$ as indicated in the caption, starting from a saturated $*$ NO layer. Before and after the application of $E_{\text {step, }}$ a potential of $+0.85 \mathrm{~V}_{\mathrm{RHE}}$ was applied. (c and d) FTIR spectra starting with a complete $\mathrm{NO}$ adlayer at $+0.85 \mathrm{~V}_{\mathrm{RHE}}$ in $\mathrm{H}_{2} \mathrm{O}$ and $\mathrm{D}_{2} \mathrm{O}$, respectively. The reference spectrum was obtained at $+0.85 \mathrm{~V}_{\mathrm{RHE}}$. The electrolyte was $0.1 \mathrm{M} \mathrm{HClO}_{4}$.

adsorbed NO species via a Langmuir-Hinshelwood $(\mathrm{L}-\mathrm{H})$ mechanism is feasible. It is not possible to conclude, however, whether both mechanisms take place or if the $\mathrm{L}-\mathrm{H}$ mechanism is the only mechanism for $\mathrm{N}_{2} \mathrm{O}$ formation, favored at high coverages that are maintained with $\mathrm{NO}$ in solution.

The integration of the two *NO stripping peaks in Figure 1a yields a charge of $410 \mu \mathrm{C} \mathrm{cm}$-2 for NO reduction (after 
correction for the hydrogen adsorption). Assuming that this charge originates from the transfer of five electrons per $* \mathrm{NO}$ molecule (i.e., for the complete reduction to $\left.\mathrm{NH}_{4}^{+}\right), \theta_{* \mathrm{NO}}$ at saturation is calculated at $0.4 \mathrm{ML}$ for $\mathrm{Pt}(111) .,{ }^{5}$

Saturated *NO layers were reduced by applying a constant potential $\left(E_{\text {step }}\right)$ between +0.25 and $+0.42 \mathrm{~V}_{\mathrm{RHE}}$ [where $\mathrm{NO}$ (top) is reduced during the voltammetry]. The currentversus-time transients recorded in parallel (Figure $1 \mathrm{~b}$ ) show a monotonic decay characteristic of a first-order reaction with strong lateral interactions. ${ }^{13} \mathrm{We}$ were able to control the coverage of the remaining ${ }^{*} \mathrm{NO}$ by controlling the $E_{\text {step }}$ or the time of the chronoamperometric experiment. It was not meaningful, however, to record spectra during the chronoamperometric transients, because of the long time required to record one spectrum with a sufficient signal-to-noise ratio $(\sim 45$ $\mathrm{s}$ for 100 interferograms). The generated nonsaturated *NO adlayers were afterward again protected from further reduction by application of $+0.85 \mathrm{~V}_{\mathrm{RHE}}$ and characterized using LSV starting from the same potential. From the comparison with the LSV of the full *NO layer (Figure 1a), it is evident that only the wave for the reduction atop NO has diminished. Moreover, the shape of the LSVs for the nonsaturated *NO layers is the same as for the saturated layer; i.e., *NO on the fcc hollow sites and the remaining atop $* \mathrm{NO}$ are reduced at the same potential as for the saturated $* \mathrm{NO}$ adlayer.

3.3. Reduction of *NO on $\mathrm{Pt}(100)$. We further studied the interaction of $\mathrm{NO}$ with $\mathrm{Pt}(100)$. It is known that a $\mathrm{Pt}(100)$ surface prepared by high-temperature annealing in ultrahigh vacuum can be reconstructed as a $(5 \times 20)$ hexagonal structure. $^{54}$ However, molecular NO adsorption under the same conditions lifts the reconstruction, ${ }^{55}$ while the $\operatorname{Pt}(100)$ electrode is unreconstructed in the electrochemical environment independent of the applied potential. ${ }^{56}$ Therefore, we consider that the electrochemical experiments presented below take place always on the unreconstructed $\operatorname{Pt}(100)-(1 \times 1)$ surface.

On $\mathrm{Pt}(100)$, the LSV for a saturated *NO adlayer (black curve in Figure 2a) shows only a single, sharp reductive peak at approximately $+0.27 \mathrm{~V}_{\mathrm{RHE}}$ while no features from the blank NO-free $\mathrm{Pt}(100)$ voltammogram are observed at more positive potentials, again because of the complete surface deactivation by *NO. ${ }^{7}$ The single peak is assigned to the reduction of *NO(bridge), which is the most stable *NO adsorption site independent of its coverage as described above.

The infrared spectra on $\mathrm{Pt}(100)$ show a bipolar band for NO at $+0.50 \mathrm{~V}_{\mathrm{RHE}}$ centered at $1630 \mathrm{~cm}^{-1}$, which is assigned to the shift of the vibrational frequency of $* \mathrm{NO}$ (bridge) from 1640 $\mathrm{cm}^{-1}$ at $+0.85 \mathrm{~V}_{\mathrm{RHE}}$ to $1620 \mathrm{~cm}^{-1}$ at $+0.50 \mathrm{~V}_{\mathrm{RHE}}$ (Figure $2 \mathrm{~d}$ for $\left.\mathrm{D}_{2} \mathrm{O}\right){ }^{9}$ As seen on $\mathrm{Pt}(111)$, we observe a strong positive band at $1461 \mathrm{~cm}^{-1}$ and a weak positive band at $2230 \mathrm{~cm}^{-1}$ at +0.2 $\mathrm{V}_{\mathrm{RHE}}$ (Figure $2 \mathrm{c}$ for $\mathrm{H}_{2} \mathrm{O}$ ), indicating that $\mathrm{NH}_{4}{ }^{+}$is the main product of $\mathrm{NO}$ reduction, but some $\mathrm{N}_{2} \mathrm{O}$ also forms in parallel via a Langmuir-Hinshelwood mechanism. The calculated $\theta_{*_{N} O}$ on $\mathrm{Pt}(100)$ at saturation is $0.5 \mathrm{ML}$, using the charge associated with *NO reduction and assuming a five-electron reduction. ${ }^{6}$

The current transients for which $+0.27 \mathrm{~V}<E_{\text {step }}<+0.3 \mathrm{~V}$ with initially saturated $* \mathrm{NO}$ adlayers are remarkably different from those on $\mathrm{Pt}(111)$. On $\mathrm{Pt}(100)$, after the initial monotonic current decay, a bell-shaped current transient is observed at longer times (Figure $2 \mathrm{~b}$ ). The bell-shaped transient shifts to shorter times, and the current peak increases after application of a less positive $E_{\text {step }}$. Such bell-shaped transients have been observed previously for NO reduction on $\mathrm{Pt}(110)$ electrodes. ${ }^{13}$
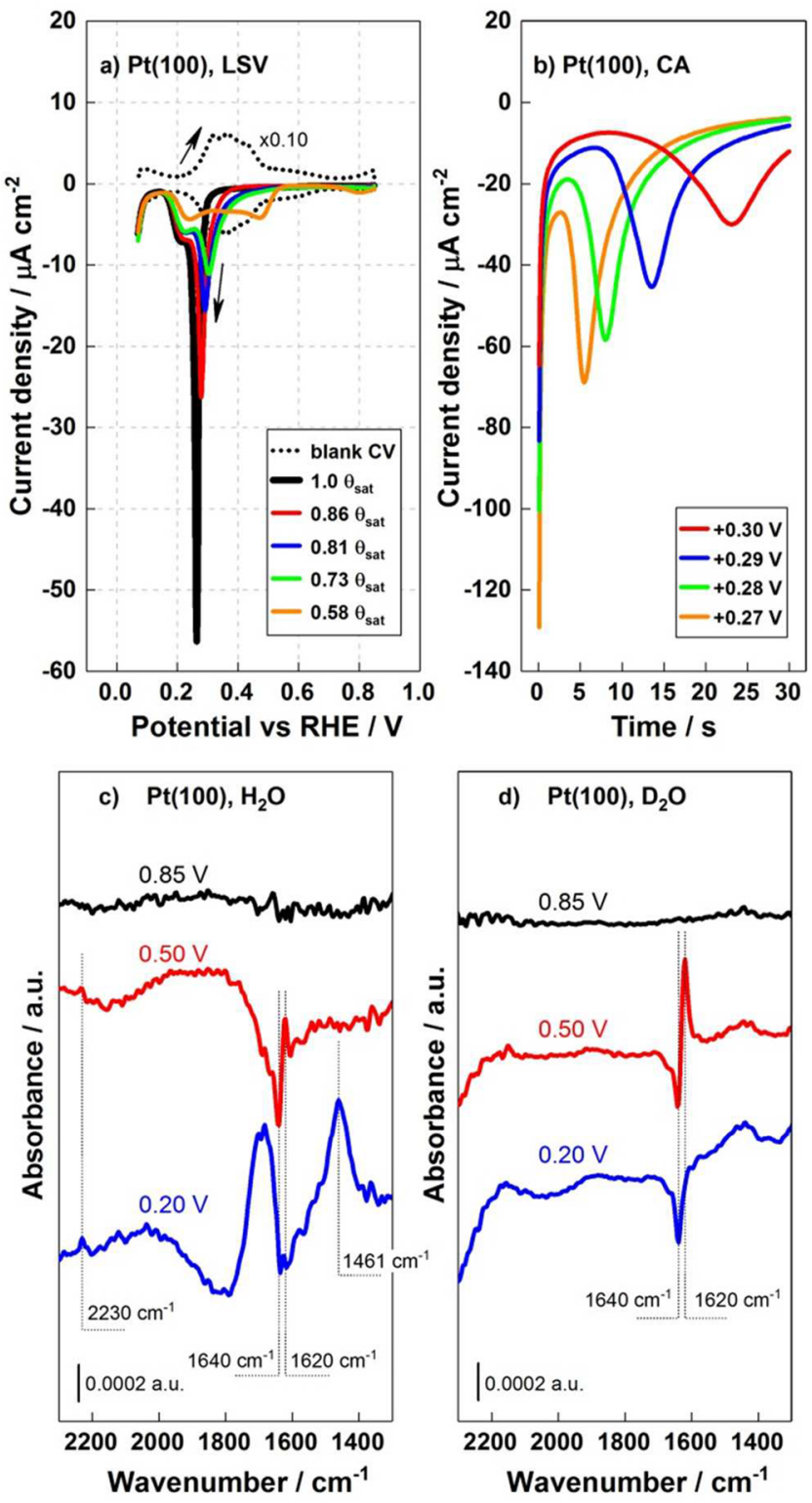

Figure 2. Same as Figure 1, for $\mathrm{Pt}(100)$.

The shape of the transient points toward first-order kinetics at high coverages (short times) and second-order kinetics at low coverages (longer times). ${ }^{13}$ The reaction order appears to be entirely controlled by the surface coverage: the plot of the reductive current versus the coverage (calculated from integration of the $i-t$ curve for all times) shows that the transition from first- to second-order kinetics always occurs at a certain critical coverage, regardless of the potential (Figure S1).

Another striking difference between $\mathrm{Pt}(111)$ and $\mathrm{Pt}(100)$ is evident from the LSVs of the incomplete layers. On Pt(100), the $* \mathrm{NO}$ reduction starts at more positive potentials when the *NO coverage is lower (Figure 2a), indicating that *NO(bridge) in a less dense layer requires a lower overpotential for its reduction.

The incomplete $\mathrm{NO}$ adlayers were also characterized via in situ infrared spectroscopy. Figure 3 shows the spectra in $\mathrm{D}_{2} \mathrm{O}$ for a complete layer and for incomplete layers of $\mathrm{NO}$ on $\mathrm{Pt}(100)$, with the reference spectrum at $+0.20 \mathrm{~V}_{\mathrm{RHE}}$, i.e., at a potential where NO is no longer present on the surface. Thus, 


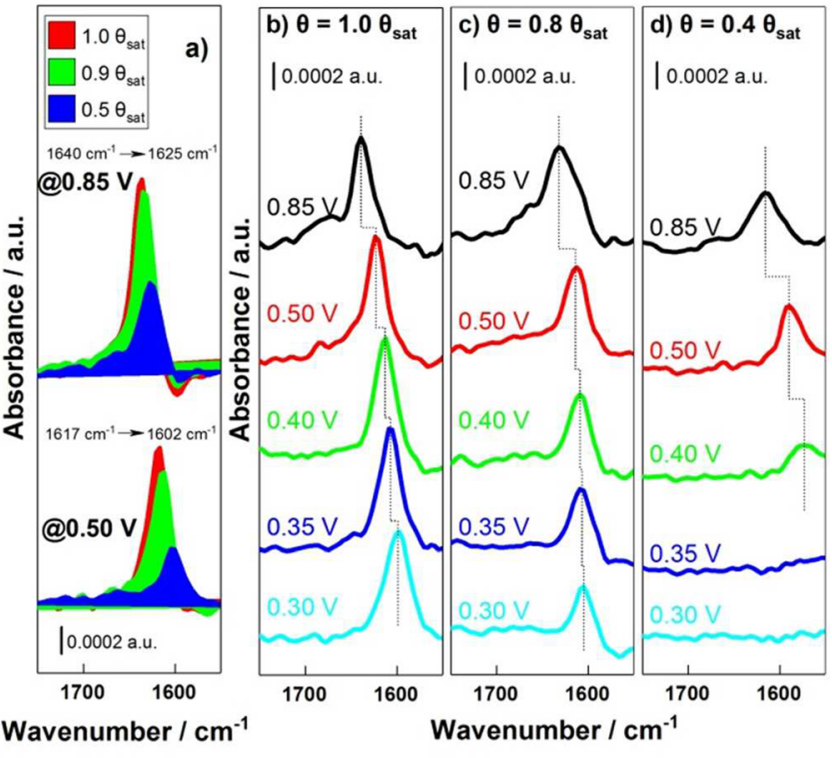

Figure 3. FTIR spectra for complete and incomplete layers of $\mathrm{NO}$ on $\mathrm{Pt}(100)$. The spectra were recorded in $\mathrm{D}_{2} \mathrm{O}$ and $0.1 \mathrm{M} \mathrm{HClO}_{4}$ and are expressed with reference to the spectrum at $+0.2 \mathrm{~V}_{\mathrm{RHE}}$. In panel a, we compare the spectra for different $\mathrm{NO}$ coverages, at +0.85 and $+0.50 \mathrm{~V}$. In panels $\mathrm{b}-\mathrm{d}$, we compare the spectra for different potentials, at initial NO coverages of $0.5,0.4$, and $0.2 \mathrm{ML}$.

positive bands in Figure 3 imply that NO is present at the sample potential.

We first compare the spectra at different coverages of $\mathrm{NO}$ at +0.85 and $+0.50 \mathrm{~V}_{\mathrm{RHE}}$ in Figure $3 \mathrm{a}$. With a decrease in NO coverage, the $\mathrm{N}-\mathrm{O}$ stretching frequency shifts to lower wavenumbers, i.e., from 1640 to $1625 \mathrm{~cm}^{-1}$ at $+0.85 \mathrm{~V}_{\mathrm{RHE}}$ or from 1617 to $1602 \mathrm{~cm}^{-1}$ at $+0.50 \mathrm{~V}_{\mathrm{RHE}}$, for a decrease in coverage from 0.5 to $0.25 \mathrm{ML}$. The coverages are approximations based on the area of the bands relative to the area for the complete NO adlayer in the beginning of the experiment. Thus, an incomplete NO adlayer is characterized by a lower frequency for the $\mathrm{N}-\mathrm{O}$ stretching compared to the saturated layer, at the same potential.

Figure $3 \mathrm{~b}-\mathrm{d}$ shows the spectra at different initial NO coverages, for potentials from +0.85 to $+0.3 \mathrm{~V}_{\mathrm{RHE}}$. For the complete NO layer (Figure $3 b$ ), the positive band for NO shifts only with the potential but the intensity of the band is the same at all potentials measured, indicating that the NO adlayer is stable and the Stark shift is the only effect of the applied potential on the adsorbed NO layer. When the initial coverage with NO is lower (Figure 3c), the intensity of the band decreases slightly by decreasing the potential below $+0.4 \mathrm{~V}_{\mathrm{RHE}}$, implying that the NO coverage decreases accordingly. Interestingly, when the initial NO coverage is significantly lower (Figure 3d), the applied potential has a stronger impact on the intensity of the NO-related band, which is no longer present at potentials below $+0.4 \mathrm{~V}_{\mathrm{RHE}}$. Therefore, the results in Figure $3 \mathrm{~b}-\mathrm{d}$ provide unambiguous evidence that $\mathrm{NO}$ adsorbed at lower coverages is more reactive than NO present on $\mathrm{Pt}(100)$ in a saturated $\mathrm{NO}$ adlayer, confirming the interpretation of the linear sweep voltammograms in Figure 2a.

3.4. DFT Calculations on the *NO Hydrogenation Steps. We analyzed by means of DFT calculations the effect of the platinum surface configuration, namely, (111) or (100), and the effect of the surface $* \mathrm{NO}$ coverage on the energetics of the reaction steps from $* \mathrm{NO}$ to $\mathrm{NH}_{4}^{+}$(Figure 4). We set the

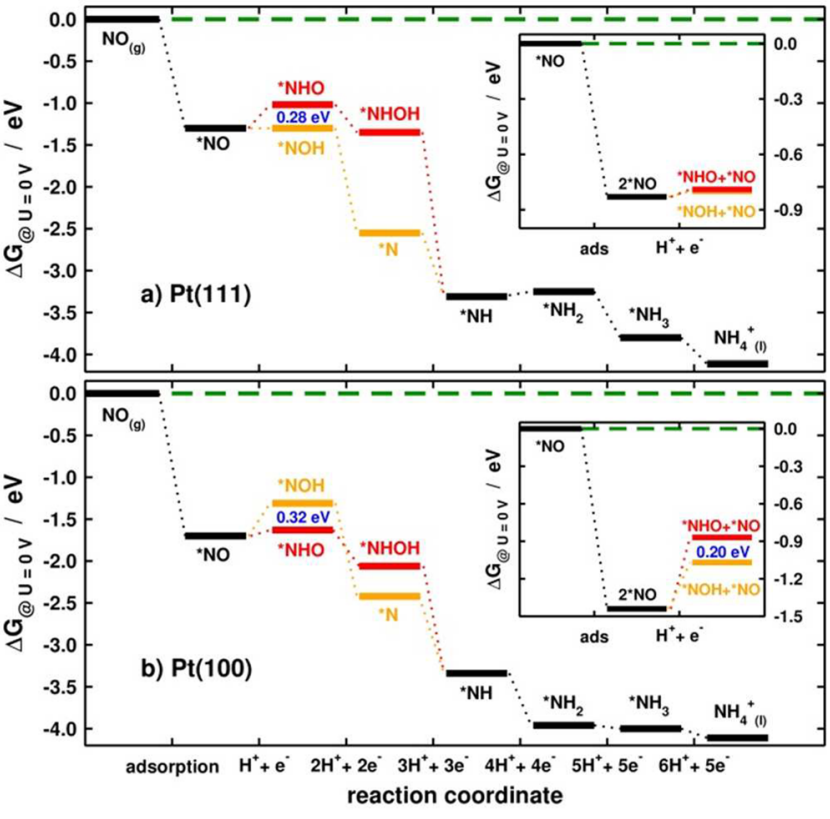

Figure 4. Energetics of the structure-sensitive reduction of $\mathrm{NO}$ on $\mathrm{Pt}$ electrodes: (a) $\mathrm{Pt}(111)$ and (b) $\mathrm{Pt}(100)$, at $\theta_{*_{\mathrm{NO}}}=0.25 \mathrm{ML}$. The reaction proceeds via $\mathrm{NO}$ adsorption and subsequent hydrogenation, forming the various surface intermediates and products noted. After *NO adsorption, the pathways bifurcate and the species denoted in orange and red are the competing intermediates. The competing pathways reunite at $* \mathrm{NH}$, eventually forming the same final product, $\mathrm{NH}_{4}{ }^{+}$. Insets show the energetics of $* \mathrm{NO}$ adsorption and the first hydrogenation at $\theta_{*_{\mathrm{NO}}}=0.50 \mathrm{ML}$ for the two surfaces (see the structures in Figure S2). In all cases, the numbers in blue show the energy differences between the critical competing intermediates.

electrode potential at $0 \mathrm{~V}$, to facilitate a straightforward comparison with the works of Greeley and co-workers. ${ }^{41,57}$ Figures S2 and S3 show the adsorbate configurations for the competing pathways, which are useful for the interpretation of the energy diagrams.

On $\mathrm{Pt}(111)$ at low coverages (Figure 4a), the reduction of $* \mathrm{NO}(\mathrm{fcc})$ proceeds via $* \mathrm{NOH}$ and $* \mathrm{~N}$ adsorbates, which are also adsorbed on fcc hollow sites (Figure S3a). The formation of $* \mathrm{NOH}$ from $* \mathrm{NO}$ and the formation of $* \mathrm{NH}_{2}$ from $* \mathrm{NH}$ are potential-limiting.

For higher $\theta_{*_{\mathrm{NO}}}$ values $(\leq 0.50 \mathrm{ML})$, the situation is more complex as either $* \mathrm{NO}($ top $)$ or $* \mathrm{NO}(\mathrm{fcc})$ might be reduced. We thus calculated the energetics of the first hydrogenation step for both cases (Figure S2a). In the first scenario, i.e., $\mathrm{NO}(\mathrm{fcc})$ being hydrogenated with $\mathrm{NO}(\mathrm{top})$ as a spectator, the reaction still proceeds via $* \mathrm{NOH}(\mathrm{fcc})$, as at low coverages. In the second scenario, where $\mathrm{NO}$ (atop) is hydrogenated and $\mathrm{NO}(\mathrm{fcc})$ is a spectator, *NHO(atop) forms.

On the basis of only the inset of Figure 4a, we cannot make a claim about which of the two species, *NO(fcc) or *NO(atop), will be reduced first, as they are both equally favorable. Note also that the calculations at low coverages show that the $* \mathrm{NH}$ hydrogenation to $* \mathrm{NH}_{2}$ is also potential-limiting, so that the onset potential for the reduction of $* \mathrm{NO}$ (atop) or $* \mathrm{NO}(\mathrm{fcc})$ at high coverages may be determined by the fourth hydrogenation step. The calculation of the potential-determining step for the different pathways at high coverages would require the computationally very demanding combinatorial analysis of all steps from $* \mathrm{NO}$ to $* \mathrm{NH}_{3}$. The experimental results, however, 
suggest that the $* \mathrm{NO}$ (top) reduction takes place at more positive potentials. $^{14}$

The behavior of $\operatorname{Pt}(100)$ is qualitatively and quantitatively different from that of $\mathrm{Pt}(111)$. At low coverages, the reduction of *NO adsorbed on bridge sites is inclined toward * $\mathrm{NHO}(4-$ fold hollow) and ${ }^{*} \mathrm{NHOH}$ (bridge) as shown in Figure $4 \mathrm{~b}$ and Figure S3b. This is in contrast to the case for $\operatorname{Pt}(111)$ where the reaction goes via $* \mathrm{NOH}(\mathrm{fcc})$ for the same coverage. The pathway via *NHO is preferred on $\mathrm{Pt}(100)$ because of the more stable bidentate adsorption configuration of $* \mathrm{NHO}$, which binds to four Pt atoms on hollow sites (Figure S3b). However, at high $\theta_{* \text { NO }}$ values, monodentate ${ }^{*} \mathrm{NOH}$ on a bridge site dominates in view of the low surface availability and deleterious lateral interactions (Figure S2b and inset of Figure 4b).

A noteworthy observation from Figure $4 \mathrm{~b}$ and its inset is that the first hydrogenation product is more stable (relative to $* \mathrm{NO})$ at low $\theta_{*_{\mathrm{NO}}}$ values (*NHO) compared to high $\theta_{*_{\mathrm{N}} \mathrm{O}}$ values $(* \mathrm{NOH})$. This implies that the onset potential for the reduction of $* \mathrm{NO}$ is expected to be more positive at low coverages, assuming that the first electrochemical step is potential-limiting at high coverages. Contrary to the case for $\mathrm{Pt}(111)$, here it is reasonable to assume that the potentialdetermining step at high coverages is the first hydrogenation step, considering that this is clearly the case at low coverages and that all further steps are exothermic.

3.5. Proposed Scheme for the *NO Reduction on $\mathrm{Pt}(111)$ and $\mathrm{Pt}(100)$. Combining our theoretical and experimental results, we propose the following scheme for the structure- and coverage-sensitive reduction of $\mathrm{NO}$ on $\mathrm{Pt}$ electrodes (see Figure 5).

On $\mathrm{Pt}(111)$, ${ }^{*} \mathrm{NO}(\mathrm{fcc})$ and $* \mathrm{NO}$ (top) are present at the surface at high coverages. $* \mathrm{NO}$ (top) is reduced at more positive potentials in the region from +0.40 to $+0.25 \mathrm{~V}_{\mathrm{RHE}}{ }^{14}$ The reduction of $* \mathrm{NO}$ (top) proceeds via $* \mathrm{NHO}$ (top), while $* \mathrm{NO}(\mathrm{fcc})$ remains a spectator (Figure $5 \mathrm{~b}$ ). The chronoamperometric results show that first-order kinetics is followed, which is explained by the fact that $* \mathrm{NO}$ (top) and $* \mathrm{NHO}$ (top) occupy the same number of atoms (in the case in which hydrogenation of $* \mathrm{NH}$ to $* \mathrm{NH}_{2}$ is potential-limiting, the reaction involves only a single active site). Once * $\mathrm{NO}$ (top) reduction is complete and the *NO coverage is lower, a potential of less than $+0.25 \mathrm{~V}_{\mathrm{RHE}}$ is required to reduce $* \mathrm{NO}(\mathrm{fcc})$ via $* \mathrm{NOH}(\mathrm{fcc})$ (Figure 5a). Therefore, the coverage on $\mathrm{Pt}(111)$ affects the nature of the adsorbed/reactive species, e.g., $\mathrm{NO}$ (top) or $\mathrm{NO}(\mathrm{fcc})$ at high or low coverages, respectively, but the individual hydrogenation mechanisms of $\mathrm{NO}$ (top) (via *NHO) or $\mathrm{NO}(\mathrm{fcc})$ (via $* \mathrm{NOH}$ ) are independent of the coverage. This is why two reduction waves are observed on $\mathrm{Pt}(111)$ and why the individual onset potentials do not shift with the coverage.

On $\mathrm{Pt}(100)$, only * $\mathrm{NO}$ (bridge) is adsorbed at high and low coverages. Initially, this species is reduced via $* \mathrm{NHO}$ (bridge) following first-order kinetics as both adsorbates occupy equal numbers of $\mathrm{Pt}$ atoms (Figure $5 \mathrm{~d}$ ). To activate $* \mathrm{NO}$ (bridge) at this high coverage, a potential of less than $+0.3 \mathrm{~V}_{\mathrm{RHE}}$ is required. As the coverage decreases and surface atoms become available, *NO(bridge) is preferentially reduced via * $\mathrm{NHO}(4-$ fold hollow), following second-order kinetics with respect to $\theta_{*_{\mathrm{NO}}}$, which is explained by the fact that $* \mathrm{NHO}$ occupies twice the number of atoms that $* \mathrm{NO}$ does (Figure 5c). Given that * $\mathrm{NHO}$ (4-fold hollow) is significantly more stable than $* \mathrm{NOH}$ (bridge), the hydrogenation of $* \mathrm{NO}$ at low coverages

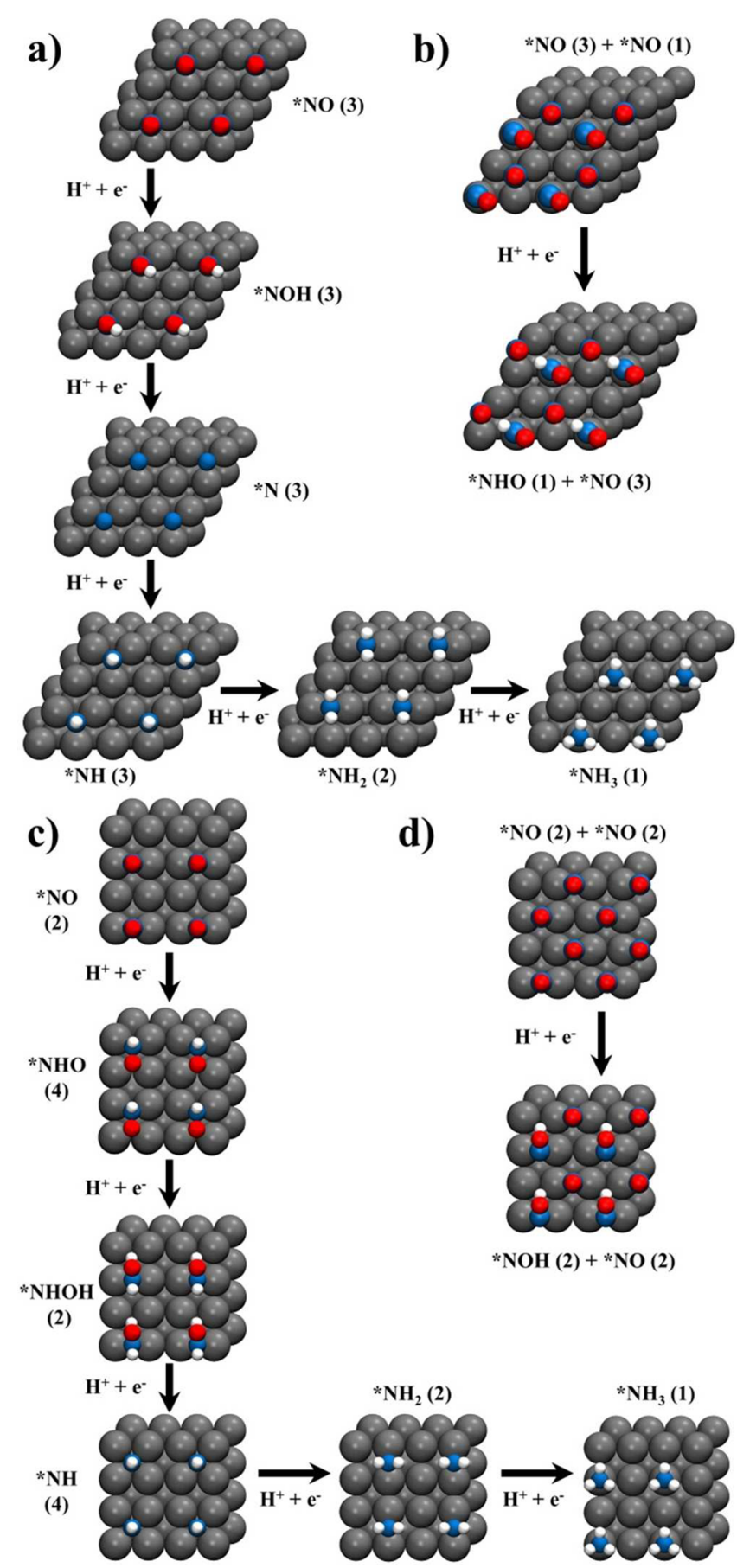

Figure 5. Most stable adsorbed reaction intermediates of NO reduction on Pt electrodes: ( $a$ and $b) \operatorname{Pt}(111)$ and (c and d) $\mathrm{Pt}(100)$. Panels a and $\mathrm{c}$ and panels $\mathrm{b}$ and $\mathrm{d}$ correspond to low and high coverages, respectively. The surface coordination of the adsorbates appears in parentheses.

starts at more positive potentials. The reason why the reduction of $* \mathrm{NO}$ does not proceed via $* \mathrm{NHO}$ at high coverages is that there are no available atoms to accommodate the 4-fold *NHO adsorbate (Figure S2b). A striking difference between $\mathrm{Pt}(111)$ and $\mathrm{Pt}(100)$ is that in the latter the change in the coverage induces directly a change in the reaction mechanism of the same species, $\mathrm{NO}$ (bridge).

Before closing the discussion, we analyze our results in the context of materials design. The results and the scheme 
described above show that the mechanism of $*$ NO reduction is sensitive to the surface coverage and the surface structure. If one determines a reaction mechanism on $\mathrm{Pt}(111)$ at low $* \mathrm{NO}$ coverages and extrapolates to high coverages, it is erroneously recommended to enhance the stabilization of $* \mathrm{NOH}$ to reduce the overpotential, because the adsorbate present under those conditions is $* \mathrm{NHO}$. Furthermore, if one extrapolates the lowcoverage mechanism found for (111) to (100) at an identical coverage, the mistake would be the same. These qualitative subtleties restrict the predictive power of descriptor-based analyses, introduce sizable errors into the models [as large as $\sim 0.2-0.3 \mathrm{eV}$ (see the blue numbers in Figure 4)], and might lead to inappropriate design rules, as stabilizing $* \mathrm{NHO}$ is different from stabilizing $* \mathrm{NOH}$, in view of their different adsorption configurations.

Finally, note that $* \mathrm{NO}, * \mathrm{NOH}$, and $* \mathrm{NHO}$ adsorption configurations change depending on the surface geometry and the coverage (see Figures 5, S2, and S3). They can adsorb on hollow, bridge, or top sites, and this is what ultimately introduces the differences between facets and coverages. For instance, while bidentate adsorption is favored on squaresymmetry facets and low coverages, high coverages and hexagonal symmetry prevent multifold adsorption. Avoiding lateral interactions is so stabilizing in this case that * NHO switches from 3-fold, bidentate adsorption at low coverages to atop monodentate adsorption at high coverages.

\section{CONCLUSIONS}

In summary, we have shown that the reduction of pre-adsorbed $\mathrm{NO}$ on $\mathrm{Pt}(111)$ and $\mathrm{Pt}(100)$ is dependent on the surface facet and surface coverage, in terms of reaction mechanism, onset potential, and reaction order. The DFT calculations offer an explanation for the experimental observations based on the relative stability of the adsorbed intermediates and their surface coordination.

We have presented here an example of a reaction that exhibits mechanistic sensitivity on the surface structure and coverage with adsorbates, so different intermediates are formed even though the final product is the same. Our results indicate that when descriptor-based analyses assume a single catalytic pathway the errors can be significant. Thus, a common reaction pathway should be a fulfilled condition rather than a blind assumption, so that more accurate predictions of catalytic activities can be drawn from materials screening routines.

\section{ASSOCIATED CONTENT}

\section{S Supporting Information}

The Supporting Information is available free of charge on the ACS Publications website at DOI: 10.1021/acscatal.7b01069.

Energies for NO adsorption on different sites on $\mathrm{Pt}(111)$ and $\mathrm{Pt}(100)$ from DFT, calculations for high coverage, current-versus-coverage dependence during the chronoamperometric experiments on $\mathrm{Pt}(100)$, and slab thickness tests for $\mathrm{Pt}(111)$ and $\mathrm{Pt}(100)$ (PDF)

\section{AUTHOR INFORMATION}

\section{Corresponding Authors}

*E-mail: i.katsounaros@fz-juelich.de.

*E-mail: f.calle.vallejo@chem.leidenuniv.nl.

*E-mail: m.koper@chem.leidenuniv.nl.

ORCID

Ioannis Katsounaros: 0000-0001-6462-710X
Federico Calle-Vallejo: 0000-0001-5147-8635

Marc T. M. Koper: 0000-0001-6777-4594

\section{Present Address}

${ }^{\dagger}$ I.K.: Forschungszentrum Jülich $\mathrm{GmbH}$, Helmholtz Institute Erlangen-Nürnberg for Renewable Energy (IEK-11), Egerlandstraße 3, 91058 Erlangen, Germany.

\section{Notes}

The authors declare no competing financial interest.

\section{ACKNOWLEDGMENTS}

I.K. acknowledges support by a Marie Curie International Outgoing Fellowship within the seventh European Community Framework Programme (Award IOF-327650). X.C. acknowledges support from the China Scholarship Council (Grant 201506220154). F.C.-V. acknowledges funding from NWO (Veni Project 722.014.009). The use of supercomputing facilities at SURFsara was sponsored by NWO Physical Sciences, with financial support by NWO.

\section{REFERENCES}

(1) Moncada, S.; Palmer, R. M.; Higgs, E. A. Pharmacol. Rev. 1991, 43, 109-142.

(2) Rosca, V.; Duca, M.; de Groot, M. T.; Koper, M. T. M. Chem. Rev. 2009, 109, 2209-2244.

(3) Gorte, R. J.; Schmidt, L. D.; Gland, J. L. Surf. Sci. 1981, 109, 367380.

(4) Villegas, I.; Gomez, R.; Weaver, M. J. J. Phys. Chem. 1995, 99, 14832-14839.

(5) Rodes, A.; Gómez, R.; Pérez, J. M.; Feliu, J. M.; Aldaz, A. Electrochim. Acta 1996, 41, 729-745.

(6) Rodes, A.; Gómez, R.; Orts, J. M.; Feliu, J. M.; Aldaz, A. J. Electroanal. Chem. 1993, 359, 315-323.

(7) Gómez, R.; Rodes, A.; Orts, J. M.; Feliu, J. M.; Pérez, J. M. Surf. Sci. 1995, 342, L1104-L1110.

(8) Rodes, A.; Gómez, R.; Orts, J. M.; Feliu, J. M.; Pérez, J. M.; Aldaz, A. Langmuir 1995, 11, 3549-3553.

(9) Rodes, A.; Climent, V.; Orts, J. M.; Pérez, J. M.; Aldaz, A. Electrochim. Acta 1998, 44, 1077-1090.

(10) Beltramo, G. L.; Koper, M. T. M. Langmuir 2003, 19, 89078915.

(11) Rosca, V.; Koper, M. T. M. J. Phys. Chem. B 2005, 109, 1675016759.

(12) Rosca, V.; Beltramo, G. L.; Koper, M. T. M. Langmuir 2005, 21, $1448-1456$

(13) Rosca, V.; Koper, M. T. M. Surf. Sci. 2005, 584, 258-268.

(14) Cuesta, A.; Escudero, M. Phys. Chem. Chem. Phys. 2008, 10, $3628-3634$.

(15) Taylor, H. S. Proc. R. Soc. London, Ser. A 1925, 108, 105-111.

(16) Zambelli, T.; Wintterlin, J.; Trost, J.; Ertl, G. Science 1996, 273, $1688-1690$

(17) van Santen, R. A. Acc. Chem. Res. 2009, 42, 57-66.

(18) Adžić, R. R.; Tripković, A. V.; O’Grady, W. E. Nature 1982, 296, 137-138.

(19) Markovic, N.; Ross, P. N. Surf. Sci. Rep. 2002, 45, 117-229.

(20) Koper, M. T. M. Nanoscale 2011, 3, 2054-2073.

(21) Cao, D.; Lu, G.-Q.; Wieckowski, A.; Wasileski, S. A.; Neurock, M. J. Phys. Chem. B 2005, 109, 11622-11633.

(22) Wang, H.-F.; Liu, Z.-P. J. Am. Chem. Soc. 2008, 130, 1099611004.

(23) Lai, S. C. S.; Lebedeva, N. P.; Housmans, T. H. M.; Koper, M. T. M. Top. Catal. 2007, 46, 320-333.

(24) Greeley, J.; Jaramillo, T. F.; Bonde, J.; Chorkendorff, I.; Nørskov, J. K. Nat. Mater. 2006, 5, 909-913.

(25) Stephens, I. E. L.; Bondarenko, A. S.; Grønbjerg, U.; Rossmeisl, J.; Chorkendorff, I. Energy Environ. Sci. 2012, 5, 6744-6762. 
(26) Calle-Vallejo, F.; Tymoczko, J.; Colic, V.; Vu, Q. H.; Pohl, M. D.; Morgenstern, K.; Loffreda, D.; Sautet, P.; Schuhmann, W.; Bandarenka, A. S. Science 2015, 350, 185-189.

(27) Calle-Vallejo, F.; Pohl, M. D.; Reinisch, D.; Loffreda, D.; Sautet, P.; Bandarenka, A. S. Chem. Sci. 2017, 8, 2283-2289.

(28) Diaz-Morales, O.; Ledezma-Yanez, I.; Koper, M. T. M.; CalleVallejo, F. ACS Catal. 2015, 5, 5380-5387.

(29) Halck, N. B.; Petrykin, V.; Krtil, P.; Rossmeisl, J. Phys. Chem. Chem. Phys. 2014, 16, 13682-13688.

(30) Peterson, A. A.; Nørskov, J. K. J. Phys. Chem. Lett. 2012, 3, 251258.

(31) Clavilier, J.; El Actii, K.; Petit, M.; Rodes, A.; Zamakhchari, M.

A. J. Electroanal. Chem. Interfacial Electrochem. 1990, 295, 333-356.

(32) Climent, V.; Feliu, J. M. J. Solid State Electrochem. 2011, 15, 1297-1315.

(33) Pourbaix, M. Atlas of Electrochemical Equilibria in Aqueous Solutions, 1st ed.; Pergamon Press: Oxford, U.K., 1966; pp 493-503.

(34) Iwasita, T.; Nart, F. C. Prog. Surf. Sci. 1997, 55, 271-340.

(35) Kresse, G.; Furthmüller, J. Phys. Rev. B: Condens. Matter Mater.

Phys. 1996, 54, 11169-11186.

(36) Kresse, G.; Joubert, D. Phys. Rev. B: Condens. Matter Mater. Phys.

1999, 59, 1758-1775.

(37) Perdew, J. P.; Burke, K.; Ernzerhof, M. Phys. Rev. Lett. 1996, 77, $3865-3868$.

(38) Tripkovic, V.; Hansen, H. A.; Rossmeisl, J.; Vegge, T. Phys. Chem. Chem. Phys. 2015, 17, 11647-11657.

(39) Monkhorst, H. J.; Pack, J. D. Phys. Rev. B 1976, 13, 5188-5192.

(40) Nørskov, J. K.; Rossmeisl, J.; Logadottir, A.; Lindqvist, L.;

Kitchin, J. R.; Bligaard, T.; Jónsson, H. J. Phys. Chem. B 2004, 108, 17886-17892.

(41) Clayborne, A.; Chun, H.-J.; Rankin, R. B.; Greeley, J. Angew. Chem., Int. Ed. 2015, 54, 8255-8258.

(42) Tripković, V.; Skúlason, E.; Siahrostami, S.; Nørskov, J. K.; Rossmeisl, J. Electrochim. Acta 2010, 55, 7975-7981.

(43) He, Z.-D.; Hanselman, S.; Chen, Y.-X.; Koper, M. T. M.; CalleVallejo, F. J. Phys. Chem. Lett. 2017, 8, 2243-2246.

(44) Shen, J.; Kolb, M. J.; Göttle, A. J.; Koper, M. T. M. J. Phys. Chem. C 2016, 120, 15714-15721.

(45) Calle-Vallejo, F.; Krabbe, A.; García-Lastra, J. M. Chem. Sci. 2017, 8, 124-130.

(46) Peterson, A. A.; Abild-Pedersen, F.; Studt, F.; Rossmeisl, J.; Nørskov, J. K. Energy Environ. Sci. 2010, 3, 1311-1315.

(47) Calle-Vallejo, F.; Koper, M. T. M. Angew. Chem., Int. Ed. 2013, $52,7282-7285$.

(48) Koper, M. T. M.; van Santen, R. A.; Wasileski, S. A.; Weaver, M. J. J. Chem. Phys. 2000, 113, 4392-4407.

(49) Ibach, H.; Lehwald, S. Surf. Sci. 1978, 76, 1-12.

(50) Dunn, D. S.; Severson, M. W.; Hylden, J. L.; Overend, J. J. Catal. 1982, 78, 225-237.

(51) Gland, J. L.; Sexton, B. A. Surf. Sci. 1980, 94, 355-368.

(52) Hayden, B. E. Surf. Sci. 1983, 131, 419-432.

(53) de Vooys, A. C. A.; Koper, M. T. M.; van Santen, R. A.; van Veen, J. A. R. Electrochim. Acta 2001, 46, 923-930.

(54) Van Hove, M. A.; Koestner, R. J.; Stair, P. C.; Bibérian, J. P.; Kesmodel, L. L.; Bartoš, I.; Somorjai, G. A. Surf. Sci. 1981, 103, 189217.

(55) Gardner, P.; Tüshaus, M.; Martin, R.; Bradshaw, A. M. Surf. Sci. 1990, 240, 112-124.

(56) Tidswell, I. M.; Marković, N. M.; Ross, P. N. Phys. Rev. Lett. 1993, 71, 1601-1604.

(57) Chun, H.-J.; Apaja, V.; Clayborne, A.; Honkala, K.; Greeley, J. ACS Catal. 2017, 7, 3869-3882. 